\title{
BMJ Open Current and future use of point-of-care tests in primary care: an international survey in Australia, Belgium, The Netherlands, the UK and the USA
}

Jeremy Howick, ${ }^{1}$ Jochen W L Cals, ${ }^{2}$ Caroline Jones, ${ }^{1}$ Christopher P Price, ${ }^{1}$ Annette Plüddemann, ${ }^{1}$ Carl Heneghan, ${ }^{1}$ Marjolein Y Berger, ${ }^{3}$ Frank Buntinx, ${ }^{2,4}$ John Hickner, ${ }^{5}$ Wilson Pace, ${ }^{6}$ Tony Badrick, ${ }^{7}$ Ann Van den Bruel, ${ }^{1}$ Caroline Laurence, ${ }^{8}$ Henk C van Weert, ${ }^{9}$ Evie van Severen, ${ }^{4}$ Adriana Parrella, ${ }^{8}$ Matthew Thompson ${ }^{10}$

To cite: Howick J, Cals JWL, Jones $\mathrm{C}$, et al. Current and future use of point-of-care tests in primary care: an international survey in Australia, Belgium, The Netherlands, the UK and the USA. BMJ Open 2014;4: e005611. doi:10.1136/ bmjopen-2014-005611

- Prepublication history and additional material is available. To view please visit the journal (http://dx.doi.org/ 10.1136/bmjopen-2014005611).

Received 2 May 2014 Revised 17 June 2014 Accepted 17 July 2014

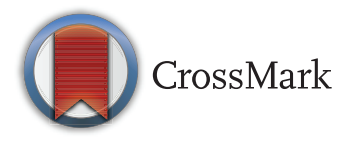

For numbered affiliations see end of article.

Correspondence to Dr Jeremy Howick; Jeremy.howick@phc.ox.ac.uk

\section{ABSTRACT}

Objective: Despite the growing number of point-ofcare (POC) tests available, little research has assessed primary care clinician need for such tests. We therefore aimed to determine which POC tests they actually use or would like to use (if not currently available in their practice).

Design: Cross-sectional survey.

Setting: Primary care in Australia, Belgium (Flanders region only), the Netherlands, the UK and the USA.

Participants: Primary care doctors (general practitioners, family physicians).

Main measures: We asked respondents to (1) identify conditions for which a POC test could help inform diagnosis, (2) from a list of tests provided: evaluate which POC tests they currently use (and how frequently) and (3) determine which tests (from that same list) they would like to use in the future (and how frequently).

Results: 2770 primary care clinicians across five countries responded. Respondents in all countries wanted POC tests to help them diagnose acute conditions (infections, acute cardiac disease, pulmonary embolism/deep vein thrombosis), and some chronic conditions (diabetes, anaemia). Based on the list of POC tests provided, the most common tests currently used were: urine pregnancy, urine leucocytes or nitrite and blood glucose. The most commonly reported tests respondents expressed a wish to use in the future were: D-dimer, troponin and chlamydia. The UK and the USA reported a higher actual and desired use for POC tests than Australia, Belgium and the Netherlands. Our limited data suggest (but do not confirm) representativeness.

Conclusions: Primary care clinicians in all five countries expressed a desire for POC tests to help them diagnose a range of acute and chronic conditions. Rates of current reported use and desired future use were generally high for a small selection of POC tests, but varied across countries. Future research is warranted to explore how specific POC tests might improve primary care.

\section{Strengths and limitations of this study}

- This is the first survey assessing primary care clinician (family doctor) use and desire for point-of-care tests.

- In total, 2770 respondents across five countries (Australia, Belgium, the Netherlands, the UK and the USA) responded to the survey.

- The study identified a clinical need for a variety of point-of-care tests that will inform policy decisions about which tests might be used in primary care, and industry strategy regarding which point-of-care tests require further development.

- Response rates varied across countries, and representativeness (although suggestive) could not be confirmed.

\section{BACKGROUND}

Diagnostic testing forms the backbone of a large proportion of primary healthcare, informing decisions about treatment, specialty referral and hospital admission. Over the past few decades, diagnostic technologies have become cheaper, smaller, and in some cases more accurate. A wide range and growing $^{1}{ }^{2}$ number of point-of-care (POC, 'near patient') tests which provide rapid 'on site' results are now available. These may have potential to improve outcomes in primary care by optimising prescribing decisions, reducing referrals, improving efficiency of care and decreasing costs. ${ }^{3} 10$

While growing in number, POC tests have not generally been adopted in primary care in many high-income settings. A recent systematic review of primary care clinicians' attitudes towards blood POC tests highlighted a number of barriers, as well as potential 
facilitators, to their wider adoption in primary care. ${ }^{11}$ Barriers included concerns about accuracy, over-reliance on tests and limited usefulness. Facilitators included improved diagnostic certainty, targeting of treatment, communication and shared decisions. Concern about the evidence base for the effectiveness of POC tests was noted over 15 years ago ${ }^{12}$ and remains a problem, with few high-quality studies focusing on patient outcomes (rather than test accuracy). ${ }^{13}$

Understanding which POC tests primary care clinicians (general practitioners, family physicians) consider priorities could bridge the gap between the number of tests available and the number actually used in primary care. Understanding clinician priorities has also been shown as a key step in the successful development (by industry) and implementation of new tests. ${ }^{14}$ Yet an obstacle to assessing priorities is that clinicians may currently be unaware of some newly available technologies, and are unlikely to know what could feasibly be developed in the (near) future. Likewise, industry may not be familiar with the tests or research avenues that are likely to benefit general practice. In spite of the many benefits of understanding which POC tests clinicians find useful, there has been little effort to assess primary care clinician needs (or perceived needs) for POC tests. ${ }^{5}$

Our aim was therefore to conduct an international survey of primary care clinicians in five countries with well-developed yet different primary care health systems: Australia, Belgium, the Netherlands, the UK and the USA. Specifically, we aimed: (1) to identify the conditions for which general practitioners would find POC tests useful to help them make diagnostic decisions, (ii) evaluate which POC tests primary care clinicians use in their current practice and (iii) determine what POC tests they would like to use but are not currently available in their practices. An advantage of our approach was that the questions focused on the conditions for which the responder considered a POC test might be of value in decision-making.

\section{METHODS}

\section{Study design}

We conducted an international cross-sectional survey of primary care clinicians in Australia, Belgium (Flanders region only), the Netherlands, the UK and the USA.

\section{The survey}

We first asked primary care clinicians to identify up to five health conditions for which POC testing might help them to in making diagnostic decisions. We specified that they could list the condition whether or not a POC test currently exists (in the UK version of the survey we also asked similar questions about reducing referrals and monitoring acute conditions. Because these questions were not asked in other countries we do not report them in this international report. These data will be reported separately). Respondents also had the option to state: "I do not believe POC Tests would help me make a diagnosis." Next, we presented a list of 50 tests and asked respondents to identify which tests were available to them and they currently used as POC tests. All 50 tests were POC blood, urine or other specimen tests (as opposed to POC devices such as blood pressure monitors or electrocardiography). We did not require respondents to specify the condition for which they might use the test. Respondents were then presented with the same list (minus the tests they previously stated were already available to them) and asked them to indicate which they would wish to have available as a POC test in their practice. Hence, for each of the 50 tests primary care clinicians could indicate 1 of 4 options:

1. (Current use) This test is available as a POC test in my practice and I use it.

2. (Current use) This test is available as a POC test in my practice, but I do not use it.

3. (Desired use) This test is not available as a POC test in my practice, but I would use it if were available.

4. (Desired use) This test is not available as a POC test in my practice, and I would not use it if it were available.

For respondents who stated that they either currently used or desired to use a test, we followed up with a question about how frequently they used/desired to use the test (at least once daily, weekly, monthly, once per year or less).

Finally, respondents were asked to indicate the distance between their practice and the nearest emergency department, how long it took them (on average) to get results from a blood test, the type of location of their practice (urban, rural), the number of registered patients in their practice, how many hours per week they worked (on average), their year of qualification, age and sex. The complete version of the UK survey is in online supplementary appendix VI.

\section{Survey development and implementation}

After development by five authors (JH, CJ, MT, CH and JWLC) the survey was checked for relevance and omissions by authors in all countries, pilot tested by 30 primary care clinicians in the UK and adjusted accordingly. The list of 50 tests used in the survey was based on the most commonly ordered laboratory tests by primary care in Oxfordshire, UK, and was modified based on input from general practitioners in other countries. The survey underwent additional changes to make it relevant to each country. For example, the Australian version did not ask about use or desire for protein/creatinine ratio because protein/creatinine ratio is known in Australia as albumin:creatinine ratio (ACR) or urinary microalbumin; leucocytes/nitrites testing was excluded from the Australian survey due to survey length restrictions. Neither Belgium nor the Netherlands asked about use/ desire for prothrombin time testing because of overlap (and therefore confusion) with international normalised ratio (INR). The survey was translated to Dutch for the 
Netherlands and Belgium (translation led by JWLC) so respondents could complete the survey in their own language. In Belgium, the Netherlands, the UK and the USA, the surveys were conducted using online survey tools. In Australia the survey was conducted both online and via postal mailings (see table 1). Up to three reminders were sent in each country.

Our target sample size ranged between 357 (for Belgium with 5000 practising family care physicians) and 383 (for the USA with 208, 807 primary care physicians) based on $95 \% \pm 5 \%$ CI and an estimated proportion of $50 \% .^{1516}$

\section{Statistical analyses}

Data were entered and analysed using Excel. Respondent characteristics were compared with known characteristics of primary care clinicians in each country, based on publically available data on primary care clinician characteristics.

We categorised responses to the open-ended question (about conditions for which respondents would like POC tests to help them make diagnoses) using the International Classification of Primary Care (ICPC-2-R) ${ }^{17}$ system (see online supplementary appendix VII). We then generated frequencies of responses using SPSS (V.21) or (in Australia) Stata (V.13). Some modification of the ICPC-2-R was required to account for the responses. For example, many respondents listed cancer as a condition for which they would like a POC test, yet cancer is not currently a condition in the ICPC handbook. We also combined some conditions. For example, many respondents listed pulmonary embolism (PE) and deep vein thrombosis (DVT) as a single condition, whereas others listed these separately, so we combined PE and DVT into a single category. Four authors $(\mathrm{JH}, \mathrm{MT}$, JWLC and $\mathrm{AVdB}$ ) were responsible for modifying the coding frame. One person conducted the coding in each country, and ambiguities were resolved by discussion with additional authors. Descriptive statistics were used to display frequencies for each (adapted) ICPC-2-R condition, and a list was compiled of all tests that were actually used or desired by at least $25 \%$ of respondents in each individual country. The individual country data for tests that at least $25 \%$ of respondents either use or would use are reported in the web appendix, tables I-V. These tables also provide details about how frequently respondents used (or would use) the test.

\section{RESULTS}

\section{Sample characteristics}

A total of 2770 primary care clinicians responded to the survey (see table 1). Response rates varied from $10 \%$ (Australia) to 68\% (UK). Between 29\% (USA) and 43\% (UK) of the respondents were women, and the average distance between the practice and the nearest hospital ranged from 7.1 (Belgium) to $11.2 \mathrm{~km}$ (UK). The proportion of rural/semirural respondents ranged from $25 \%$
(USA) to 55\% (Belgium). The average year of qualification ranged from 1988 (Australia) to 1993 (UK).

\section{Representativeness}

Australian respondents reported working fewer hours per week than the national average (28 vs 33) and there was an over-representation of rural respondents $(44 \%$ rural, whereas the national average is $30 \%) .{ }^{18}$ In Belgium $40 \%$ of respondents were women and the average year of qualification was 1990, whereas on average $28 \%$ of primary care clinicians are women and the average year of qualification is 1987 in the region. ${ }^{19}$ Respondents in the Netherlands were similar to national averages in terms of age (average age 48.9 years and national average 48.5 years), and average number of hours worked per week (44 for respondents and national average).$^{20}$ Respondents in the UK were representative of UK general practitioners in terms of percentage female $43 \%$ of respondents and $48 \%$ UK general practitioners) and median year of qualification: 1996 for respondents and 1997 for national average (national average data provided median but not mean, whereas table 1 reports mean in order to retain consistency with data reported in other countries). ${ }^{21}$ In the USA the sample had fewer female respondents (29\%) than the national average (39\%) and the proportion of rural respondents was slightly higher among respondents $(25 \%)$ than the national average $(19 \%) .{ }^{22}$ These results suggest that our samples were broadly representative, yet the lack of comparative national average data prevents us from drawing firm conclusions.

\section{Conditions for which primary care clinicians would like to use a POC test to help make a diagnosis}

Table 2 displays the top 10 conditions which primary care clinicians most commonly reported wanting POC tests to help them diagnose. The most commonly listed conditions by country were: urinary tract infection (Australia, the UK and the USA) and PE/DVT (Belgium and the Netherlands). Respondents in all five countries included urinary tract infections, diabetes, acute cardiac disease and anaemia among the top 10 conditions. Respondents in at least four countries included heart failure and PE/DVT among the top 10 conditions.

\section{POC tests that primary care clinicians currently use}

Table 3 shows current use of POC tests, ranked in descending order according to the total percentage of primary care clinicians who currently use each test. Blood glucose, urine pregnancy test and urine leucocytes or nitrite were the most frequently used POC tests in the five countries, all being used by more than $80 \%$ of respondents. Beyond the top three tests, frequency of current use differed across countries. Overall, more respondents in the UK and the USA reported using POC tests than respondents in the other countries. At least $10 \%$ of respondents reported using 47 of the tests in the USA and 46 of the tests in the UK. The number 
Table 1 Characteristics of respondents in each country

\begin{tabular}{|c|c|c|c|c|c|}
\hline Country & Australia & Belgium & The Netherlands & UK & USA \\
\hline $\begin{array}{l}\text { Total number of } \\
\text { respondents }\end{array}$ & 298 & 319 & 639 & 1109 & 405 \\
\hline Response rate & $10 \%$ & NA & $30 \%$ & $68 \%$ & NA \\
\hline $\begin{array}{l}\text { Dates of data } \\
\text { collection }\end{array}$ & $\begin{array}{l}\text { Sent out May 2013, one } \\
\text { reminder, closed in October } \\
2013\end{array}$ & $\begin{array}{l}\text { Sent out February 2013, no } \\
\text { reminder, closed March } 2013\end{array}$ & $\begin{array}{l}\text { Sent out February } \\
2013 \text {, one } \\
\text { reminder, closed } \\
\text { March } 2013\end{array}$ & $\begin{array}{l}\text { Sent out September } \\
\text { 2012, three reminders } \\
\text { closed October } 2012\end{array}$ & $\begin{array}{l}\text { December } 2013 \text { through } \\
\text { February, } 2014\end{array}$ \\
\hline Female (\%) & NA & $131(40)$ & $239(37)$ & $475(43)$ & $119(29)$ \\
\hline $\begin{array}{l}\text { Kilometres to nearest } \\
\text { hospital (average) } \\
\text { Location of practice }\end{array}$ & NA & 7.1 & 8.6 & 11.2 & 7.9 \\
\hline Rural or semirural & $280(44 \%)$ & $176(55 \%)$ & $280(44 \%)$ & 377 (34\%) & $102(25 \%)$ \\
\hline Urban or suburban & $359(56 \%)$ & $143(45 \%)$ & $359(56 \%)$ & $732(66 \%)$ & $303(75 \%)$ \\
\hline $\begin{array}{l}\text { Number of patients } \\
\text { registered at practice } \\
\text { (average) }\end{array}$ & NA & 2800 & 4110 & 8275 & NA \\
\hline Sampling method & $\begin{array}{l}2933 \text { GPs Australian Medical } \\
\text { Association membership list } \\
\text { with addition of data from other } \\
\text { sources (approximately } 80 \% \\
\text { GPs covered) }\end{array}$ & $\begin{array}{l}\text { Existing mailing list of GPs and } \\
\text { GP groups in the region were } \\
\text { contacted. The survey was } \\
\text { only sent to GPs in Flanders } \\
\text { (the Flemish speaking part of } \\
\text { Belgium) }\end{array}$ & $\begin{array}{l}\text { All GPs in three } \\
\text { regionally } \\
\text { distributed GP } \\
\text { networks } \\
\text { approached }\end{array}$ & $\begin{array}{l}\text { Randomly sampled, } \\
\text { stratified according to } \\
\text { age, length of time in } \\
\text { practice, specialty and } \\
\text { location }\end{array}$ & $\begin{array}{l}\text { AAFP National Research } \\
\text { network and a randomly } \\
\text { sampled group of practitioners, } \\
\text { stratified according to age, } \\
\text { length of time in practice, } \\
\text { specialty and location }\end{array}$ \\
\hline Source & $\begin{array}{l}\text { Australasian Medical } \\
\text { Publishing Company Data } \\
\text { Direct }\end{array}$ & $\begin{array}{l}\text { Academic networks and GP } \\
\text { groups of the region } \\
\text { collectively contacted }\end{array}$ & $\begin{array}{l}\text { GPs in three } \\
\text { regions of } \\
\text { departments of } \\
\text { general practice }\end{array}$ & Doctors.net & $\begin{array}{l}\text { Practice Based Research } \\
\text { Network and commercial polling } \\
\text { agency }\end{array}$ \\
\hline Type of survey & Electronic and paper & Electronic & Electronic & Electronic & Electronic \\
\hline $\begin{array}{l}\text { Year qualified as a } \\
\text { doctor: average }\end{array}$ & 1988 & 1990 & 1991 & 1993 & 1990 \\
\hline
\end{tabular}


Table 2 Conditions for which respondents would like a point-of-care test to help them diagnose conditions: top 10 in each country

\begin{tabular}{|c|c|c|c|c|c|c|c|c|c|}
\hline \multicolumn{2}{|l|}{ Australia $(n=298)$} & \multicolumn{2}{|l|}{ Belgium $(n=319)$} & \multicolumn{2}{|c|}{ The Netherlands $(n=639)$} & \multicolumn{2}{|l|}{ UK $(n=1109)$} & \multicolumn{2}{|l|}{ USA ( $n=405)$} \\
\hline Condition & $\begin{array}{l}\text { Per cent } \\
\text { (n) }\end{array}$ & Condition & $\begin{array}{l}\text { Per cent } \\
\text { (n) }\end{array}$ & Condition & $\begin{array}{l}\text { Per cent } \\
\text { (n) }\end{array}$ & Condition & $\begin{array}{l}\text { Per cent } \\
\text { (n) }\end{array}$ & Condition & $\begin{array}{l}\text { Per cent } \\
\text { (n) }\end{array}$ \\
\hline Diabetes & $57(170)$ & PE/DVT & $94(300)$ & PE/DVT & $106.5(651)^{*}$ & UTI & $47(521)$ & UTI & $56(225)$ \\
\hline Acute cardiac disease & $42(126)$ & Acute cardiac disease & $76(241)$ & $\begin{array}{l}\text { Acute cardiac } \\
\text { disease }\end{array}$ & $62.7(383)$ & PE/DVT & $43(478)$ & Strep throat & $54(218)$ \\
\hline UTI & $32(95)$ & Heart failure & $24(75)$ & $\begin{array}{l}\text { Chest infection/ } \\
\text { cough/LRTI }\end{array}$ & $54.7(334)$ & Diabetes & $35(385)$ & Diabetes & 42 (169) \\
\hline Pregnancy & $26(79)$ & $\begin{array}{l}\text { Chest infection/ } \\
\text { cough/LRTI }\end{array}$ & $24(75)$ & UTI & 26.0 (159) & $\begin{array}{l}\text { Acute cardiac } \\
\text { disease }\end{array}$ & $25(282)$ & Influenza & $40(162)$ \\
\hline Anaemia & $18(53)$ & Infections & $23(74)$ & Heart failure & $22.9(140)$ & INR/anticoagulation & 18 (199) & Pregnancy & $25(103)$ \\
\hline $\begin{array}{l}\text { Chronic and acute renal } \\
\text { conditions (excluding UTI) }\end{array}$ & $15(45)$ & UTI & $19(61)$ & Anaemia & $20.0(122)$ & Pregnancy & $16(178)$ & $\begin{array}{l}\text { Infectious } \\
\text { mono }\end{array}$ & $14(56)$ \\
\hline INR/anticoagulation & $17(51)$ & $\begin{array}{l}\text { Acute and chronic } \\
\text { renal impairment }\end{array}$ & $12(39)$ & Diabetes & $14.7(90)$ & Anaemia & $15(162)$ & Anaemia & $13(52)$ \\
\hline PE/DVT & $13(40)$ & Diabetes & $12(37)$ & Infections & $13.1(80)$ & Heart failure & $11(124)$ & STDs & $7(27)$ \\
\hline Heart failure & $12(37)$ & Anaemia & $8(24)$ & Appendicitis & $10.8(66)$ & COPD/asthma & $10(116)$ & INR & 7 (27) \\
\hline COPD/asthma & $12(35)$ & STDs & $7(21)$ & STDs & $9.0(55)$ & $\begin{array}{l}\text { Chest infection/ } \\
\text { cough/LRTI }\end{array}$ & $9(102)$ & $\begin{array}{l}\text { Acute cardiac } \\
\text { disease }\end{array}$ & $6(23)$ \\
\hline
\end{tabular}

${ }^{*}>100 \%$ Since we combined PE and DVT. This is because some respondents in the Netherlands listed both PE and PE/DVT. In other countries we faced similar problems. Since it was impossible to split PE from DVT when respondents listed PE/DVT as a single condition, we lumped them together.

COPD, chronic obstructive pulmonary disease; DVT, deep vein thrombosis; INR, international normalised ratio; LRTI, lower respiratory tract infection; PE, pulmonary embolism; STD, sexually transmitted disease; UTI, urinary tract infection. 
Table 3 Point-of-care tests that at least $25 \%$ of respondents in at least one country reported currently using, ranked in descending order according to total percentage of general practitioners that reported using the tests

\begin{tabular}{|c|c|c|c|c|c|c|}
\hline & $\begin{array}{l}\text { Australia } \\
(n=298)\end{array}$ & $\begin{array}{l}\text { Belgium } \\
(n=319)\end{array}$ & $\begin{array}{l}\text { The Netherlands } \\
(n=639)\end{array}$ & $\begin{array}{l}\text { UK } \\
(n=1109)\end{array}$ & $\begin{array}{l}\text { USA } \\
(n=405)\end{array}$ & $\begin{array}{l}\text { Total } \\
(n=2770)\end{array}$ \\
\hline Urine pregnancy test & $68 \%(203)$ & $61 \%(193)$ & $94 \%(603)$ & $80 \%(887)$ & $86 \%(350)$ & $81 \%(2236)$ \\
\hline Urine leucocytes or nitrite & NA & $87 \%(275)$ & $96 \%(611)$ & $90 \%(993)$ & $88 \%(355)$ & $81 \%(2234)$ \\
\hline Blood glucose & $74 \%(221)$ & $87 \%(278)$ & $96 \%(616)$ & $69 \%(760)$ & $82 \%(334)$ & $80 \%(2209)$ \\
\hline INR & $48 \%(144)$ & $12 \%(37)$ & $1 \%(6)$ & $43 \%(476)$ & $47 \%(189)$ & $31 \%(852)$ \\
\hline Haemoglobin & $10 \%(29)$ & $3 \%(8)$ & $58 \%(371)$ & $16 \%(174)$ & $50 \%(202)$ & $28 \%(784)$ \\
\hline Faecal occult blood & $6 \%(19)$ & $18 \%(56)$ & $2 \%(14)$ & $13 \%(143)$ & $83 \%(335)$ & $20 \%(567)$ \\
\hline $\begin{array}{l}\text { Throat swab for group A } \\
\text { streptococci }\end{array}$ & $6 \%(19)$ & $4 \%(12)$ & $1 \%(4)$ & $15 \%(164)$ & $86 \%(348)$ & $20 \%(547)$ \\
\hline $\mathrm{C}$ reactive protein & $3 \%(8)$ & $3 \%(10)$ & $48 \%(305)$ & $15 \%(163)$ & $10 \%(42)$ & $19 \%(528)$ \\
\hline $\begin{array}{l}\text { Quantitative } \beta \text {-human } \\
\text { chorionic gonadotropin }\end{array}$ & $6 \%(18)$ & $19 \%(59)$ & $22 \%(138)$ & $17 \%(193)$ & $28 \%(112)$ & $19 \%(520)$ \\
\hline $\mathrm{HbA1c}$ & $6 \%(17)$ & $2 \%(6)$ & $6 \%(38)$ & $17 \%(183)$ & $40 \%(162)$ & $15 \%(406)$ \\
\hline $\begin{array}{l}\text { Nose/throat swab for } \\
\text { influenza }\end{array}$ & $7 \%(20)$ & $1 \%(3)$ & $0 \%(2)$ & $6 \%(61)$ & $60 \%(242)$ & $12 \%(328)$ \\
\hline Platelet count & $4 \%(11)$ & $0 \%(1)$ & $1 \%(3)$ & $15 \%(163)$ & $28 \%(112)$ & $10 \%(290)$ \\
\hline
\end{tabular}

HbA1c; glycated haemoglobin; INR, international normalised ratio; NA, not applicable.

of tests reported as used by at least $10 \%$ of respondents in the other countries was lower: five in Australia, seven in Belgium and nine in the Netherlands. The number of tests used could be a function of practice size (which was much higher in the UK than other countries where it was reported, see table 1).

A POC test for INR was used by nearly half of the Australian, American and British primary care clinicians, compared with only $1 \%(6 / 639,95 \%$ CI $0 \%$ to $2 \%)$ of the Dutch and $12 \%(37 / 319,95 \%$ CI $9 \%$ to $16 \%)$ of Belgian (Flemish) primary care clinicians. Haemoglobin tests were used by more respondents in the Netherlands $(58 \%, 371 / 639,95 \%$ CI $54 \%$ to $62 \%)$ and the USA $(50 \%, 202 / 405,95 \%$ CI $45 \%$ to $55 \%)$ than in other countries. Haemoglobin use was $16 \%(174 / 1109,95 \%$ CI $14 \%$ to $18 \%)$ in the UK, $3 \%(8 / 319,95 \%$ CI $1 \%$ to $5 \%$ ) in Belgium and $10 \%(29 / 298,95 \%$ CI $7 \%$ to $12 \%)$ in Australia. POC tests were used by a higher proportion of respondents in the USA compared with other countries. For example, $60 \%$ used throat swabs for influenza and $86 \%$ tested for group A streptococci, while these tests were used by between $0 \%$ and $15 \%$ of primary care clinicians in the other countries. Similarly, $83 \%$ of US doctors used faecal occult blood tests, while only 2-18\% of primary care clinicians in the other countries used this POC test. C reactive protein (CRP) was used by $48 \%$ $(305 / 639,95 \%$ CI $44 \%$ to $52 \%)$ of the Dutch primary care clinicians, in contrast with less than $15 \%$ in the other countries (see table 3 for details).

\section{Desired POC tests (that primary care clinicians do not} currently use but would use if available)

Desired use was higher than reported current use, suggesting a demand for POC tests (see table 4). Overall 19 tests were desired by at least $50 \%$ of respondents in at least one country, while only 8 tests were actually used by at least $50 \%$ of respondents in at least one country. POC tests for D-dimer, troponin, chlamydia, gonnorrhoea, B-type natriuretic peptide, CRP, glycated haemoglobin, white cell count and haemoglobin were desired by more than half of respondents across all countries.

Desire for POC tests was highest in the UK, where at least $50 \%$ of respondents expressed the desire to use 18 of the listed tests. The numbers of tests desired by at least $50 \%$ of respondents in other countries were: 12 (Belgium), 11 (US A), 6 (the Netherlands) and 1 (Australia). Reported current use seemed to be inversely correlated with higher desired use. For example, INR actual use in the Netherlands $(1 \%, 6 / 639,95 \%$ CI $0 \%$ to $2 \%$ ) and Belgium (12\%, 37/319, 95\% CI $9 \%$ to $16 \%)$ was low, yet desire for INR was higher in Belgium (77\%, $244 / 319,95 \%$ CI $72 \%$ to $81 \%$ ) and the Netherlands (54\%, 347/639, 95\% CI $50 \%$ to $58 \%$ ) than in other countries.

\section{DISCUSSION}

This international survey of primary care clinicians indicates a desire for POC tests to help diagnose a range of acute (infections and acute cardiopulmonary) conditions and some chronic conditions (such as diabetes and anaemia). The most frequently used POC tests used currently (blood glucose, urine pregnancy and urine leucocytes/nitrites) only partially correspond with the conditions for which primary care clinicians would like POC tests to help them make diagnoses (urinary tract infection, PE/DVT and acute cardiac disease, diabetes and anaemia). This suggests an unmet clinical need for a more widely accessible range of POC tests to assist clinicians with immediate decisions (urgent referrals, or immediate treatment decisions such as the decision to treat with antibiotics). 
Table 4 Point-of-care tests that at least $50 \%$ of respondents in at least one country would use, ranked in descending order according to total percentage of general practitioners that would use the tests

\begin{tabular}{|c|c|c|c|c|c|c|}
\hline & $\begin{array}{l}\text { Australia } \\
(\mathrm{n}=298)\end{array}$ & $\begin{array}{l}\text { Belgium } \\
(n=319)\end{array}$ & $\begin{array}{l}\text { The Netherlands } \\
(\mathrm{n}=639)\end{array}$ & $\begin{array}{l}\text { UK } \\
(n=1109)\end{array}$ & $\begin{array}{l}\text { USA } \\
(n=405)\end{array}$ & $\begin{array}{l}\text { Total } \\
(\mathrm{n}=2770)\end{array}$ \\
\hline D-dimer & $41 \%(121)$ & $83 \%(265)$ & $70 \%(448)$ & $73 \%(811)$ & $62 \%(251)$ & $68 \%(1896)$ \\
\hline Troponin & $43 \%(129)$ & $85 \%(271)$ & $65 \%(418)$ & $69 \%(765)$ & $59 \%(238)$ & $66 \%(1821)$ \\
\hline Chlamydia & $49 \%(145)$ & $67 \%(212)$ & $60 \%(382)$ & $65 \%(721)$ & $66 \%(267)$ & $62 \%(1727)$ \\
\hline B-type natriuretic peptide & $28 \%(82)$ & $51 \%(164)$ & $62 \%(398)$ & $66 \%(734)$ & $60 \%(244)$ & $59 \%(1622)$ \\
\hline $\mathrm{C}$ reactive protein & $38 \%(114)$ & $75 \%(238)$ & $47 \%(302)$ & $61 \%(682)$ & $45 \%(181)$ & $55 \%(1517)$ \\
\hline Gonorrhoea & $34 \%(100)$ & $56 \%(180)$ & $51 \%(326)$ & $58 \%(645)$ & $65 \%(262)$ & $55 \%(1513)$ \\
\hline $\mathrm{HbA1c}$ & $52 \%(156)$ & $61 \%(195)$ & $37 \%(239)$ & $61 \%(679)$ & $50 \%(202)$ & $53 \%(1471)$ \\
\hline White cell count & $43 \%(127)$ & $67 \%(212)$ & $40 \%(256)$ & $60 \%(661)$ & $52 \%(212)$ & $53 \%(1468)$ \\
\hline Haemoglobin & $47 \%(139)$ & $47 \%(150)$ & $26 \%(168)$ & $72 \%(793)$ & $39 \%(159)$ & $51 \%(1409)$ \\
\hline Potassium & $33 \%(97)$ & $47 \%(150)$ & $33 \%(210)$ & $61 \%(679)$ & $57 \%(232)$ & $49 \%(1368)$ \\
\hline $\begin{array}{l}\text { International normalised } \\
\text { ratio }\end{array}$ & $21 \%(63)$ & $77 \%(244)$ & $54 \%(347)$ & $47 \%(517)$ & $43 \%(176)$ & $49 \%(1347)$ \\
\hline $\begin{array}{l}\text { Nose/throat swab for } \\
\text { influenza }\end{array}$ & $43 \%(128)$ & $59 \%(187)$ & $36 \%(231)$ & $55 \%(609)$ & $33 \%(134)$ & $47 \%(1289)$ \\
\hline $\begin{array}{l}\text { Erythrocyte sedimentation } \\
\text { rate }\end{array}$ & $29 \%(86)$ & $40 \%(128)$ & $29 \%(183)$ & $58 \%(645)$ & $48 \%(194)$ & $45 \%(1236)$ \\
\hline $\begin{array}{l}\text { Quantitative } \beta \text {-human } \\
\text { chorionic gonadotropin }\end{array}$ & $40 \%(120)$ & $56 \%(177)$ & $23 \%(149)$ & $53 \%(586)$ & $46 \%(187)$ & $44 \%(1219)$ \\
\hline Creatinine & $34 \%(102)$ & $41 \%(130)$ & $28 \%(177)$ & $53 \%(593)$ & $53 \%(214)$ & $44 \%(1216)$ \\
\hline Thyroid stimulating hormone & $32 \%(95)$ & $33 \%(105)$ & $27 \%(171)$ & $53 \%(586)$ & $62 \%(253)$ & $44 \%(1210)$ \\
\hline $\begin{array}{l}\text { Throat swab for group A } \\
\text { streptococci }\end{array}$ & $35 \%(103)$ & $60 \%(190)$ & $33 \%(208)$ & $53 \%(588)$ & $11 \%(45)$ & $41 \%(1134)$ \\
\hline Uric acid & $28 \%(82)$ & $30 \%(94)$ & $26 \%(167)$ & $50 \%(549)$ & $51 \%(205)$ & $40 \%(1097)$ \\
\hline Sodium & $30 \%(88)$ & $21 \%(66)$ & $19 \%(122)$ & $51 \%(571)$ & $42 \%(172)$ & $37 \%(1019)$ \\
\hline
\end{tabular}

While there were similarities between countries in terms of the tests used and the conditions for which respondents expressed a desire for POC tests, there were also important differences. Both actual use and reported desired use was higher in the UK and the USA (see web appendices I-V). Different reimbursement methods across countries are likely to influence actual use, as well as attitudes towards future use. For instance, the low uptake of INR POC testing in Belgium could be due to the fact that INR POC tests are not reimbursed, whereas the regular laboratory INR test would be. The Netherlands also reported lower INR usage, which could be because there are separate thrombosis clinics monitoring anticoagulation therapy in the Netherlands. In Australia, although INR is not reimbursed (whereas a centralised laboratory test would be), primary care clinicians still use it because it improves patient flow and management. Another source of intercountry variability could be differences between practice set-ups. Rural primary care clinicians in Australia or the USA are often far more isolated than rural clinicians in Europe, and ruling out a serious condition that requires immediate transfer to the nearest hospital has important logistical consequences. The differences in reimbursement and care models across countries for POC tests need to be explored further to discover whether and how specific POC tests might improve patient outcomes in specified settings. Other factors that could affect intercountry variability include: type of reimbursement (fixed price vs test cost), space and the need to accommodate a range of technologies, staff time and the need to train staff on a range of technologies, the need to change clinic organisation expertise, expertise, regulatory requirements and uncertainty about test accuracy.

\section{Strengths and limitations}

This is the first international survey of primary care clinicians on this topic. Our responses were internally validated by asking about both desire for POC tests (from a specified list) as well as conditions for which respondents would like a POC test to help them make a diagnosis. The results of the survey suggest that there is good agreement between the conditions for which POC tests are considered useful, and POC tests primary care clinicians would like to use in the future.

Response numbers exceeded target numbers in three countries, and we were able to estimate representativeness by comparing characteristics of respondents with the characteristics of primary care clinicians in each country for many important variables. However, representativeness could not be confirmed with certainty due to limited data about national primary care clinician characteristics. Specifically, over-representation of primary care clinicians interested in POC testing could have occurred despite high response rates in some countries. We also cannot assume, based on this survey, that 
the results can be generalised to other countries, especially low-income or middle-income countries.

It was somewhat surprising that some respondents reported a desire to use some tests that should (in principle) already be widely available. For example, potassium tests have been available in the USA for over two decades and take less than 3 min to conduct. Yet $57 \%$ $(232 / 405,95 \%$ CI $52 \%$ to $62 \%)$ of US respondents expressed a desire to use potassium POC tests in the future. This suggests the possibility that respondents misunderstood the question, provided invalid responses or that the test was not available in their practice. Some of the tests, for example, tests for acute cardiac disease, may not be suitable or relevant in all countries. However, this represents a mismatch between tests that may be available commercially, yet not available to a particular respondent in their particular clinic. Further research is warranted to investigate this issue.

\section{Implications for clinicians, policymakers and industry}

Conditions that primary care clinicians claim POC tests would help them diagnose, as well as POC tests that are widely desired, deserve further research and industry development to assess their roles within evidence-based diagnostic pathways. Studies of POC test clinical effectiveness will depend on adherence to quality control protocols, while cost-effectiveness studies will have to address known barriers to cost-effectiveness of diagnostic studies in general, and POC testing in particular, ${ }^{23}$ as well as the barriers to implementation such as concerns about the over-reliance on tests. Existing data about costeffectiveness of POC testing to date are mixed. The potential for POC tests to reduce costs, for example, by reducing the number of clinic visits ${ }^{24}$ is not always borne out in practice. ${ }^{25}$ Cost-effectiveness will also be test and setting specific: an Australian trial indicated that POC testing resulted in a reduction in costs for some tests (ACR) but greater for others (INR) ${ }^{26}$ Future research is warranted to determine the clinical utility and costeffectiveness of individual tests (or clusters of tests). ${ }^{24}$ More research is also warranted to investigate the barriers to implementation, some of which we have studied previously. ${ }^{11} 27$ Once this research is done, tests which are likely to improve patient care in a cost-effective way require targeting by industry for development and optimisation. Tests used in low-prevalence settings have particular problems that may require independent investigations. $^{28}$

\section{CONCLUSION}

Primary care practitioners are eager to use a variety of POC tests. Some conditions for which POC tests are deemed most useful are similar across five countries despite important differences in healthcare organisation. Future research is now warranted to investigate how and whether these POC tests can improve patient outcomes in a cost-effective way.
Author affiliations

${ }^{1}$ Nuffield Department of Primary Care Health Sciences, University of Oxford, Oxford, UK

${ }^{2}$ Deptartment of Family Medicine, CAPHRI School for Public Health and

Primary Care, Maastricht University, Maastricht, The Netherlands

${ }^{3}$ Department of General Practice, University of Groningen, Groningen,

The Netherlands

${ }^{4}$ Academic Center for General Practice, Leuven, Belgium

${ }^{5}$ Family Medicine, University of Illinois at Chicago, Chicago, Illinois, USA

${ }^{6}$ Department of Family Medicine, University of Colorado, Aurora, Colorado, USA

${ }^{7}$ Faculty of Health Sciences and Medicine, Bond University, Queensland, Australia

${ }^{8}$ Discipline of General Practice, The University of Adelaide, Adelaide,

South Australia, Australia

${ }^{9}$ Department of General Practice, University of Amsterdam, Amsterdam, The Netherlands

${ }^{10}$ Department of Family Medicine, University of Washington, Seattle, Washington, USA

Acknowledgements Gus Sohn, Sandy Young and Fasika Alem assisted with the data analysis in the USA. Ruth Davis helped organise a meeting about the paper in December 2013.

Contributors JH drafted the first manuscript. JH, MT, CJ, CPP, CH and JWLC designed the initial (UK) version of the survey. JH did the UK data analysis; JWLC, FB, MYB, HCvW and AVdB adapted the survey for Belgium (Flanders) and the Netherlands. JWLC did the data analysis for the Dutch data and EvS did the data analysis for the Belgian data. CL and TB adapted the survey for Australia. CL and AP did the data analysis for the Australian data. JH and WP adapted the survey for the USA. JH did the data analysis for the USA. All authors contributed to the decisions about how to present the data, organise the final manuscript and edit the final manuscript.

Funding This project was partly supported by educational grants from the following companies: Alere, Atlas Genetics, BD (Becton, Dickinson and Company), Ortho Clinical Diagnostics, Philips Home Clinical Monitoring (the Netherlands), Siemens Healthcare Diagnostics, and Nova Biomedical.

Competing interests $\mathrm{JH}$ was funded by the National Institute for Health Research (NIHR) School for Primary Care Research (SPCR). JWLC is supported by a Veni-grant (91614078) of the Netherlands Organisation for Health Research and Development (ZonMw). MT, CH, CPP, AvdB, AP and CJ are supported by the NIHR Diagnostic Evidence Co-operative Oxford at Oxford Health NHS Foundation Trust.

Ethics approval Because it involved asking practising clinicians about their work, ethical approval was not required in the UK, the Netherlands, Belgium or Australia. In the USA the project was reviewed and exempted by the American Academy of Family Practitioners (AAFP) Institutional Review Board as exempt research.

Provenance and peer review Not commissioned; externally peer reviewed.

Data sharing statement All data are included in the manuscript or online appendices. The translations of the survey into Dutch and Flemish are available on contacting $\mathrm{JH}$.

Open Access This is an Open Access article distributed in accordance with the Creative Commons Attribution Non Commercial (CC BY-NC 4.0) license, which permits others to distribute, remix, adapt, build upon this work noncommercially, and license their derivative works on different terms, provided the original work is properly cited and the use is non-commercial. See: http:// creativecommons.org/licenses/by-nc/4.0/

\section{REFERENCES}

1. Huckle D. Point-of-care diagnostics-is this driven by supply or demand? Expert Opin Med Diagn 2010;4:189-200.

2. Goldsmith B. Point of care testing: clinical applications, and the use of guidelines. 2011

3. Price CP, St John A, Kricka LJ. eds Point-of-care testing. Washington: AACC Press, 2010. 
4. Smith J, Holder $\mathrm{H}$, Edwards $\mathrm{N}$, et al. Securing the future of general practice: new models of primary care. Nuffield Trust, 2013.

5. Price CP, Kricka LJ. Improving healthcare accessibility through point-of-care technologies. Clin Chem 2007;53:1665-75.

6. Gialamas A, St John A, Laurence CO, et al. Point-of-care testing for patients with diabetes, hyperlipidaemia or coagulation disorders in the general practice setting: a systematic review. Fam Pract 2010;27:17-24.

7. Gialamas A, Yelland LN, Ryan P, et al. Does point-of-care testing lead to the same or better adherence to medication? A randomised controlled trial: the PoCT in General Practice Trial. Med J Aust 2009;191:487-91.

8. Cals JW, Butler CC, Hopstaken RM, et al. Effect of point of care testing for $\mathrm{C}$ reactive protein and training in communication skills on antibiotic use in lower respiratory tract infections: cluster randomised trial. BMJ 2009;338:b1374.

9. Cals JW, Schot MJ, de Jong SA, et al. Point-of-care C-reactive protein testing and antibiotic prescribing for respiratory tract infections: a randomised controlled trial. Ann Fam Med 2010;8:124-33.

10. Geersing GJ, Janssen KJ, Oudega R, et al. Excluding venous thromboembolism using point of care D-dimer tests in outpatients: a diagnostic meta-analysis. BMJ 2009;339:b2990.

11. Jones $\mathrm{CH}$, Howick J, Roberts NW, et al. Primary care clinicians' attitudes towards point-of-care blood testing: a systematic review of qualitative studies. BMC Fam Pract 2013;14:117.

12. Hobbs FD, Delaney BC, Fitzmaurice DA, et al. A review of near patient testing in primary care. Health Technol Assess 1997;1:i-iv, 1-229.

13. Hislop J, Quayyum Z, Flett G, et al. Systematic review of the clinical effectiveness and cost-effectiveness of rapid point-of-care tests for the detection of genital chlamydia infection in women and men. Health Technol Assess 2010;14:1-97. iii-iv.

14. Heneghan C, Van den Bruel A, Thompson M, et al. Diagnostics Forum 2013 Report: fast tracking the evidence for implementing diagnostic tests. Oxford: University of Oxford, 2014.

15. Moore DS, McCabe GP, Craig B. Introduction to the practice of statistics. 6th edn. Basingstoke: W.H. Freeman, 2009
16. Service NS. Sample size calculator. Statistics ABo, 2012

17. WONCA International Classification Committee. International Classification of Primary Care ICPC-2-R. 2nd edn. Oxford: Oxford University Press, 1998.

18. AlHW. Medical Workforce 2011. National health workforce series Cat. no. HWL 49. Canberra, Australia: Welfare AloHa, 2013.

19. Meeus P, Van Aubel X. Performance of general medicine in Belgium, a check-up. Health Services Research (HSR). Brussels, Belgium: (NIHDI) NlfHaDI, 2012.

20. Berg MJvd, Kolthof ED, de Bakker DH, et al. Tweede Nationale Studie naar ziekten en verrichtingen in de huisartspraktijk. De werkbelasting van huisartsen. Utrecht: NIVEL, 2004.

21. GMC. List of registered medical practitioners-statistics. London: GMC, 2012.

22. American Academy of Family Physicians. Table 2: Selected Demographic Characteristics of AAFP Members (as of 31 December 2011). 2014. http://www.aafp.org/about/the-aafp/family-medicinefacts/table-2.html (accessed 7 Apr 2014).

23. St John A, Price CP. Economic evidence and point-of-care testing Clin Biochem Rev 2013;34:61-74.

24. York Health Economics Consortium. Organisational and behavioural barriers to medical technology adoption. Coventry, UK: NHS Institute for Innovation and Improvement, 2009.

25. Laurence C, Gialamas A, Yelland L, et al. Point of care testing in general practice trial. Final report. Canberra, Australia: Department of Health and Ageing, 2008.

26. Laurence CO, Moss JR, Briggs NE, et al. The cost-effectiveness of point of care testing in a general practice setting: results from a randomised controlled trial. BMC Health Serv Res 2010;10:165.

27. Cals J, van Weert $\mathrm{H}$. Point-of-care tests in general practice: hope or hype? Eur J Gen Pract 2013;19:251-6.

28. Van den Bruel A, Haj-Hassan T, Thompson M, et al. Diagnostic value of clinical features at presentation to identify serious infection in children in developed countries: a systematic review. Lancet 2010;375:834-45. 